\title{
Minimal invasive surgery in locally advanced N2 non-small cell lung cancer
}

\author{
Ana Karina Patané \\ Department of Thoracic Surgery, Hospital de Rehabilitación Respiratoria María Ferrer, Buenos Aires, Argentina \\ Correspondence to: Ana Karina Patané. Department of Thoracic Surgery, Hospital de Rehabilitación Respiratoria María Ferrer, Enrique Finochietto \\ 849, CABA (1272), Buenos Aires, Argentina. Email: cirugiapulmon@gmail.com.
}

\begin{abstract}
Locally advanced lung cancer, defined by nodal involvement in upper mediastinal stations (N2) (stage IIIA-N2), includes a wide spectrum of patients with multiple therapeutic alternatives. Such heterogeneity is explained, at least in part, by tumor size and magnitude of mediastinal nodal involvement. In this setting, many variants can influence the prognosis, such as the specific nodal stations compromised, the burden of mediastinal disease, and the presence of skip metastasis. In the surgical field, the advent of minimally invasive techniques, including video-assisted thoracoscopic and robotic surgery, have revolutionized the management of early-stage lung cancer, but implementations of these approaches in the locally advanced setting have been erratic. This review attempts to highlight the most relevant scientific data of the surgical management of locally advanced lung cancer patients, analyzing not only the medical evidence but also the cost-effectiveness and accessibility.
\end{abstract}

Keywords: Non-small cell lung cancer (NSCLC); N2 disease; minimally invasive approach; VATS surgery; induction therapy

Submitted Feb 29, 2020. Accepted for publication Mar 12, 2020.

doi: $10.21037 /$ tlcr.2020.03.27

View this article at: http://dx.doi.org/10.21037/tlcr.2020.03.27

\section{Introduction}

In the last decade, tremendous advances in cancer treatments have improved the management of locally and advanced non-small cell lung cancer (NSCLC). In the surgery field, minimally invasive surgery (MIS), specially video-assisted thoracoscopic (VATS), has emerged as a completely nonrib spreading technique with long-term outcomes and overall oncologic efficacy equivalent to the traditional open thoracotomy (1-4). Growing experience with this technique, together with the improvement in video technology and instrumentation, has allowed the VATS to evolve from early-stage to locally advanced NSCLC (stage IIIA-N2) (5-7). VATS has demonstrated multiples advantages compared to open thoracotomy, such as reduced postoperative pain, shorter hospital stays, diminisher inflammatory responses, early onset of patients' usual activities, and better tolerance to postoperative chemotherapy (8). Since the 1990s, the emergence of the minimally invasive approach has gained ground in the surgical field for the treatment of multiple pathologies. As for early-stage lung cancer surgery, this technique went from being a subtle suggestion to a strong recommendation in clinical practice guidelines. However, the use in the advanced setting is still variable (3). The main reasons for the resistance of this new technology include the increased risk of intraoperative accidents (bleeding and vascular injury), and most importantly, the doubt of not being able to perform a radical oncologic resection compared to standard thoracotomy (8). Additionally, there is a lack of a clear consensus on what features constitute an "operable" stage IIIA-N2 NSCLC, which leads to multiple controversial issues, such as single nodal metastasis versus multi-station involvement, suspected limited versus bulky disease, and induction chemotherapy versus chemoradiation (3). For all these reasons, the aim of this review is to provide a comprehensive overview of two of the most controversial topics in NSCLC surgical treatment: mediastinal N2 lymph 
node involvement, and the minimally invasive surgical technique.

\section{Mediastinal involvement}

Diagnosis of N2 disease may occur during preoperative staging, as well as intraoperatively during lung resection (9).

\section{Role of mediastinal staging and re-staging: $\mathrm{N} 2$ detected in preoperative evaluation}

Although imaging studies, such as computed tomography and even positron emission tomography, have a high sensitivity to detect distant metastases, the specificity of these techniques is limited. In the case of suspected mediastinal metastasis, obtaining tissue for histological confirmation is mandatory, and surgical staging remains the gold standard for mediastinal evaluation (3). For that reason, the NCCN guidelines currently recommend pathological investigation of mediastinal lymph nodes during pretreatment of patients with adenocarcinoma, tumors $>3 \mathrm{~cm}$, enlarged nodes N1, stage IIB (T3, N0), and stage IIIA-N2 disease $(1,10)$. The utility of mediastinal staging in the potentially resectable N2 NSCLC is crucial, not only to confirm the mediastinal metastatic involvement but also to have an objective evaluation of the tumor response to treatment (induction therapy) to guide further therapeutic strategies.

Two classical multicenter randomized studies evaluated the benefits of surgery in patients with N2 disease. The first one, performed by the European Organization for Research and Treatment of Cancer (EORTC), randomized 332 unresectable (IIIA-N2) NSCLC patients to radiotherapy or surgery after induction chemotherapy (11). The authors found no statistical differences in terms of overall survival (OS) or progression-free survival between both strategies. However, in the surgery group, complete resection was achieved in $50 \%$ of patients. On the other hand, Albain et al. conducted a North American multicenter study, including resectable IIIA-N2 NSCLC patients (12). After induction chemotherapy, 396 patients were randomized to radiotherapy followed by surgery or definitive radiation. The surgical strategy was associated with a progression-free survival benefit, but it did not translate to OS. In a subgroup analysis comparing surgical procedures, lobectomy offered benefits in terms of OS compared to pneumonectomy, and a high mortality rate $(26 \%)$ was also associated with this major resection. Interestingly, this study showed a better prognosis for patients with a mediastinal downstaging with $41 \%$ of 5 -year survival in ypN0 cases. These two trials exposed the heterogeneity of stage IIIA-N2 tumors, in which the surgery approach could have a clear benefit in patients that achieve a complete resection. The better prognosis group includes patients with a complete response to induction therapy, as well as those with a mediastinal downstaging (ypN0-1). In the same way, Cerfolio et al. analyzed the results of a retrospective cohort of 402 patients with confirmed N2 NSCLC by mediastinal staging and treated with neoadjuvant chemo-radiotherapy (10). The study aimed to identify characteristics for accessing to surgical treatment. The authors found that patients who performed surgery [149] had a better OS compared to those without access to a surgical procedure [253] (47\% vs. 8\%, $\mathrm{P}<0.001)$. Although in the univariate analysis age under 70 years, gender, number of nodes involved, initial tumor status, and max SUV were significantly different between groups, the multivariate analysis found that age younger than 70 years $(\mathrm{P}=0.003)$, single lymph node involvement $(\mathrm{P}=0.019)$, and response to induction therapy $(\mathrm{P}=0.001)$ were predictors of better prognosis.

There is an evident controversy about the place of surgery in the multimodal treatment of stage IIIA-N2 NSCLC. Taking into account all the studies mentioned above, the surgical strategy has a potential benefit in the subset of patients with complete tumor response, mediastinal downstaging, and single nodal station disease.

\section{Unexpected N2 metastases: N2 detected intraoperatively}

Detterbeck reviewed the intraoperative management of patients with NSCLC and 'surprise' N2 disease (13). Three different types of $\mathrm{N} 2$ disease with different prognosis could be defined: the 'unsuspected N2' (intraoperatively wellstaged patients); the 'ignored N2' (suspicious mediastinal nodes according to non-invasive staging methods, who nevertheless undergo a resection without prior histological confirmation); and the 'underappreciated N2' (high suspicion of N2 involvement, such as the case of central tumor, $\mathrm{N} 1$ node enlargement, or $>3 \mathrm{~cm}$ tumors, that do not undergo an invasive staging procedure). A third of patients with 'ignored N2', and a quarter with 'underappreciated N2' will undergo incomplete resections, with a consequently very low 5-year survival prognosis ( 4\%) (13). Even more, the type of $\mathrm{N} 2$ disease influence survival in the complete resection group, with $22 \%, 35 \%$, and $41 \% 5$-year survival for 'ignored', 'underappreciated', and 'unsuspected N2', 
respectively.

For the management of intraoperative N2 disease, two possible alternatives can be proposed, such as continuing with lung resection or switching to an exploratory strategy without resection. It is essential to consider some points to choose the best option. Firstly, although the mortality of exploratory thoracotomy is similar to lung resection ( 4\%), this later approach had a decreased short-term quality of life (14). Secondly, it is expected that half of the patients with 'surprise N2' findings at thoracotomy may complete induction therapy and subsequent surgical resection (14). In this context, Yang et al. studied long-term outcomes after lobectomy for 'unsuspected pN2' disease (6). Among 46,691 patients who performed lobectomy as the primary strategy for cT1-3 N0-1 NSCLC, 2,047 (4.4\%) had "unsuspected" pN2 disease after surgical resection. For these patients, median and overall 5-year survival were 31 months [95\% confidence interval (95\% CI): 29-33] and 30\% (95\% CI: $28-32 \%)$, respectively. In the same period, lobectomy was performed in 2,302 patients after induction therapy (chemotherapy 39\%, and chemoradiotherapy 61\%) due to suspected N2 disease. In the "unsuspected N2" group, patients were older, more frequently female, having more comorbidities, lower clinical $\mathrm{T}$ status, and were more likely adenocarcinomas, compared to the "suspected N2" cases. More interestingly, 'unsuspected N2' patients had a higher number of regional lymph nodes analyzed, a more probable complete resection, and a smaller tumor size.

\section{Single versus multimodal invasion}

In an attempt to analyze the prognostic impact of the mediastinal tumor burden, Wei et al. developed a retrospective study on 1,659 patients treated surgically from 2000 to 2006, at a cancer center in Japan (15). In the analyzed group (median age 63.8 years old, $58 \%$ male, and $78.3 \%$ adenocarcinomas), the most frequent surgical procedure was lobectomy. A total of 456 patients presented lymph node metastases. Although the average number of nodes retrieved per patient was 15.9 (range, 1-79), an average of 4.11 (range, 1-29) presented metastatic involvement. The authors classified the patients into four categories: $\mathrm{nN} 0$, without lymph node involvement; $\mathrm{nN} 1$, metastasis in one or two nodes; $\mathrm{nN} 2$, three to six; and $\mathrm{nN} 3$, compromise of seven or more. Patients with pN0 and nN0 had the best prognosis, with overall 5-year survival and disease-free survival (DFS) rates of $89.2 \%$ and $83.2 \%$, respectively. A significant difference was found between $\mathrm{pN} 1$ and $\mathrm{pN} 2$ in terms 5 -year DFS $(37.3 \%$ vs. $24.5 \%, \mathrm{P}=0.026$ ), but not in OS (5-year OS rate: $55.4 \%$ vs. $47.8 \%, \mathrm{P}=0.245)$. The 5 -year $\mathrm{OS}$ rate for $\mathrm{nN} 0, \mathrm{nN} 1$, $\mathrm{nN} 2$, and $\mathrm{nN} 3$ was $89.2 \%, 65.1 \%, 42.1 \%$, and $22.4 \%$, respectively $(\mathrm{P}=0.001)$, and 5 -year DFS rate was $83.2 \%$, $44.1 \%, 23.0 \%$, and $6.5 \%$, respectively $(\mathrm{P}=0.001)$. Moreover, the survival curves showed a reduced OS and DFS when analyzing the progression from $\mathrm{nN} 0$ to $\mathrm{nN} 3$, although a significant difference was not found for all cases. The latter was particularly validated for the $\mathrm{T}$ stage. Consequently, the $\mathrm{nN}$ category was an independent prognostic factor for OS and DFS. In conclusion, this study helped to highlight that disease burden (number of metastatic lymph nodes) is a better prognosis factor than anatomic location of lymph node involvement, which may be imprecise.

\section{Skip metastases}

Skip metastases are defined by the presence of N2 metastatic disease without hilar nodal involvement (N1). A frequency between $17.2 \%$ and $42.7 \%$ has been reported in surgically resected N2 lung tumors (16). Although this phenomenon was described as a favorable independent prognosis factor compared to $\mathrm{pN} 1 \mathrm{~N} 2$ patients, nowadays, this finding is still a matter of debate $(17,18)$. In a retrospective study of 2,653 patients who underwent to complete surgical resection for N2 NSCLC, 881 cases (33.2\%) had skip metastases, and they were older, more likely to be male, smoker, with tumors of the right upper lobe, and with squamous cell carcinoma (19). Univariate Cox regression analysis showed that skip N2 metastases were associated with significantly better survival $(\mathrm{HR}=0.72, \mathrm{P}=0.002)$, and a borderline significance was observed in the multivariate analysis (HR 0.81, $\mathrm{P}=0.0698$ ). Conversely, a retrospective study about robotic resection of stage III lung cancer led by Veronesi, found that OS did not differ between cases with and without skip metastases (20).

The analysis of lung cancer patients with $\mathrm{N} 2$ mediastinal invasion is complex and heterogenous since multiples scenarios are possible. Expected versus unexpected N2 metastases, single versus multiple invasion, and also the skip metastasis phenomenon has to be discussed at the time of selecting a multimodal therapeutic strategy.

All points mentioned above, particularly the single or multiple nodal involvements, and the presence of skip metastases, were described by the 8 th edition of the TNM classification for NSCLC. All these findings have modified the descriptor $\mathrm{N}$ of this staging system. 


\section{Is lymphadenectomy appropriate when performed by MIS?}

An adequate lymphadenectomy is a crucial step in the surgical management of NSCLC. It provides a precise pathological staging and allows to be more accurate to define stages, decide the treatment strategy, and evaluate the prognosis (21). Surprisingly, around $20 \%$ of patients undergoing VATS lobectomy performed a single nodal station sampling or less, challenging the quality of VATS lymphadenectomy (22). Boffa et al. found that VATS lobectomy had a lower rate of N1 upstaging compared with thoracotomy, suggesting that peribronchial and hilar lymph node clearance may be compromised by the VATS approach (23). However, like other surgical techniques, the quality of VATS lobectomies is directly proportional to the surgeon training. Lee et al. retrospectively reviewed 500 consecutive patients with NSCLC undergoing VATS lobectomy performed majority by a senior surgeon during ten years (21). Mediastinal lymph nodes stations 4, 7, and 9 were dissected on the right side, and stations 5, 6, 7, and 9 on the left side. The mean number of lymph nodes dissected was 14 (12 for stage I, and 19 for stage II/III). The adequacy of lymphadenectomy in the early (cases from 2002 to 2010) versus late (cases from 2010 to 2012) groups was assessed. Significantly more lymph nodes were removed, and more N1 and N2 stations were sampled in the late group, which also had more pathologic N1 and N2 disease $(19 \%$ vs. $10 \%, \mathrm{P}=0.006)$. The substantial number of lymph nodes retrieved, as well as the rest of the findings of this study, highlights that VATS lymphadenectomies need experienced surgeons, with a learning curve of at least 50 procedures.

\section{Surgical techniques}

MIS is an entirely non-rib spreading technique, including some variations, such as VATS, robotic, and uniportal VATS, among others (24). Although it is possible to treat both early and locally advanced NSCLC using thoracoscopic lobectomy, the lack of consensus on its indications in stage IIIA NSCLC makes implementation extremely erratic in different institutions. For that reason, the multi-disciplinary team decisions play a pivotal role in guiding individualized treatment decisions. According to NCCN guidelines, surgery is suggested for stage IIIA with a single N2 lymph node involvement, and in tumors smaller than $3 \mathrm{~cm}$ following neoadjuvant chemotherapy (1).

\section{Video-assisted thoracoscopic lobectomy versus open lobectomy: upfront or post neoadjuvant therapy}

Despite the considerable progress achieved in the surgical field, VATS lobectomy still has some detractors arguing against the safety of the procedure, and the oncological results. On the other hand, more enthusiastic surgeons develop this practice, convinced that patients have less postoperative pain, shorter hospitalization, and a lower overall cost (25).

Three randomized clinical trials have compared VATS to open lobectomy in localized NSCLC. Kirby et al. analyzing 55 patients (25 in the VATS group and 30 in the thoracotomy group), found no significant differences in operating time, intraoperative blood loss, duration of chest tube drainage, or length of hospital stay (26). In the same way, Sugi et al. leaded a prospective trial including 100 patients with stage IA (T1N0M0) NSCLC between 1993 and 1994 (27). The authors found no difference in the number of dissected nodes using VATS or conventional lobectomy with similar 5 -year OS rates $(90 \%$ and $85 \%$, respectively, log-rank test, $\mathrm{P}=0.74)$. Additionally, Xue et al. demonstrated in 100 localized NSCLC elderly patients, that VATS had lower postoperative complications, such as forced expiratory volume, and postoperative partial pressure of arterial oxygen (28).

The comparison between thoracoscopy and thoracotomy was also studied in a recent meta-analysis by Wang et al., reviewing the most reliable evidence (29). The pooled analysis of 10 studies and 1,514 patients showed a significant reduction of almost $46 \%$ in the incidence of total postoperative complications (odds ratio $0.54, \mathrm{P}<0.0001$ ) using VATS. A decreased hospital stay ( $\mathrm{P}=0.0001)$, as wells as a shorter duration of chest tube drainage $(\mathrm{P}=0.003)$, favored VATS. Although VATS had a relatively longer operative time $(\mathrm{P}=0.02)$, no significant differences were found in numbers of resected lymph nodes and the rate of postoperative complications (pneumonia, bleeding, or postoperative mortality).

Taioli et al. also compared these two surgical approaches in a meta-analysis of 22 studies and 4,767 patients $(2,106$ with VATS, and 2,661 with open thoracotomy) (25). Interestingly, patients who underwent VATS had better 5 -year survival, but with substantial heterogeneity among studies. Although the benefit of thoracoscopy, in terms of clinical outcomes, could be explained by the selection bias of the studies included in the meta-analyses, it could also hypothesize that this may be due to the reduced number 
of cytokines released, with a consequent reduction in perioperative immunosuppression when using VATS.

The majority of MIS experience has come from earlystage disease, and data of locally advanced NSCLC, particularly following induction chemotherapy, has been limited to observational studies (Table 1) (30-35). Following a neoadjuvant approach, surgery has demonstrated to improve clinical outcomes, and VATS lobectomy was safe and as effective as open lobectomy (5). Kamel et al. described their experience with VATS lobectomy after neoadjuvant therapy (32). No difference was found in the number of lymph nodes explored, stations sampled, and $\mathrm{R} 0$ resection rates between VATS lobectomy and thoracotomy. Moreover, no difference was observed in 5-year DFS rate between VATS and thoracotomy, but the MIS approach presented a shorter hospital stay and a trend towards fewer postoperative complications.

\section{Other Surgical approaches}

\section{Uniportal VATS}

As previously exposed, despite the several advantages of VATS compared with open thoracotomy, the adoption of this MIS approach for locally advanced NSCLC is still infrequent. Intraoperative thoracoscopic major bleeding or technical complications in advanced cases hamper a high adoption. Nevertheless, the same procedure can be performed using a single incision approach. Since the development of the uniportal technique for VATS lobectomies in 2010, this technique has been adopted by many surgeons worldwide, mainly due to reduced access trauma and the advent of new instruments designed for this purpose, such as the high definition $5 \mathrm{~mm} / 30$ degrees cameras, double articulation instruments, and more angulated staplers (36).

Gonzalez-Rivas et al. analyzed retrospectively 130 uniportal VATS (including major pulmonary resection) for early and locally advanced (tumors greater than $>5 \mathrm{~cm}$, T3$\mathrm{T} 4$, or tumors requiring neoadjuvant treatment) NSCLC patients between 2010 and 2012 (8). Advanced cases had a statistically longer surgical time $(\mathrm{P}=0.001)$ and a higher median number of lymph nodes (0.004). No significant differences were observed in terms of the intensive care unit stay, days of a chest tube, and rate of complications. The authors concluded that uniportal VATS lobectomy is a safe and reliable procedure, even for more advanced NSCLC cases.
Despite the uniportal advent ten years ago, and the increasing implementation based on instrumentation advantages and encouraging perioperative results, the benefit of this technique over the two-port videothoracoscopy was not intensively studied. Surgeon training curve has been one of the main limitations of this approach, since patients with multiples comorbidities may restrict this procedure.

\section{Robotic approach}

Robotic surgery represents a technological evolution of MIS approach with several technical advantages, such as a better view of the operative field (3D instead of 2D), precise movement of the instruments which gives maneuverability even superior to that of the human hands $(37,38)$. All these advantages allow shorter surgical steps, including radical lymphadenectomy and execution of complex procedures, such as bronchoplasty and vascular dissection (39). Furthermore, the quicker recovery of the patients when using robot-assisted surgery allows initiating full-dose adjuvant chemotherapy at a prudent time (within the six weeks) after surgery $(38,40)$.

Park and colleagues retrospectively reviewed 428 locally advanced NSCLC patients treated by thoracotomy $(\mathrm{n}=397)$, robot-assisted surgery (RATS) $(\mathrm{n}=17)$, and VATS $(\mathrm{n}=14)$. Notably, open and minimally invasive techniques showed similar oncological outcomes, but the latter group had a significantly shorter hospital stay (31). An interesting retrospective analysis, performed by Veronesi et al., prospectively collected data from seven centers with RATS expertise for lung cancer resection (20). Patients with clinical or pathological stage IIIA-N2 NSCLC or carcinoid tumors were selected and treated by robot-assisted resection with curative intent pre or post-chemotherapy or chemoradiation. A total of 223 patients were analyzed, and the mean duration of surgery and hospital stay was $194 \mathrm{~min}$ (SD 82) and 5.3 days, respectively. Severe (ClavienDindo Grade III-V) postoperative complications occurred in $23(10.3 \%)$ cases but no related $(\mathrm{P}=0.14)$ to neoadjuvant chemotherapy. Interestingly, $22(9.9 \%)$ patients had to be converted to thoracotomy due to oncological (3 unforeseen mediastinal nodal involvement), bleeding [6], technical (2, including one intraoperative airway complication), and anatomical [7] reasons. Using univariable analysis, tumors size and $>2$ positive lymph nodes were the only two factors significantly associated with conversion. Importantly, negative surgical margins were obtained in $98.4 \%$ of cases. 


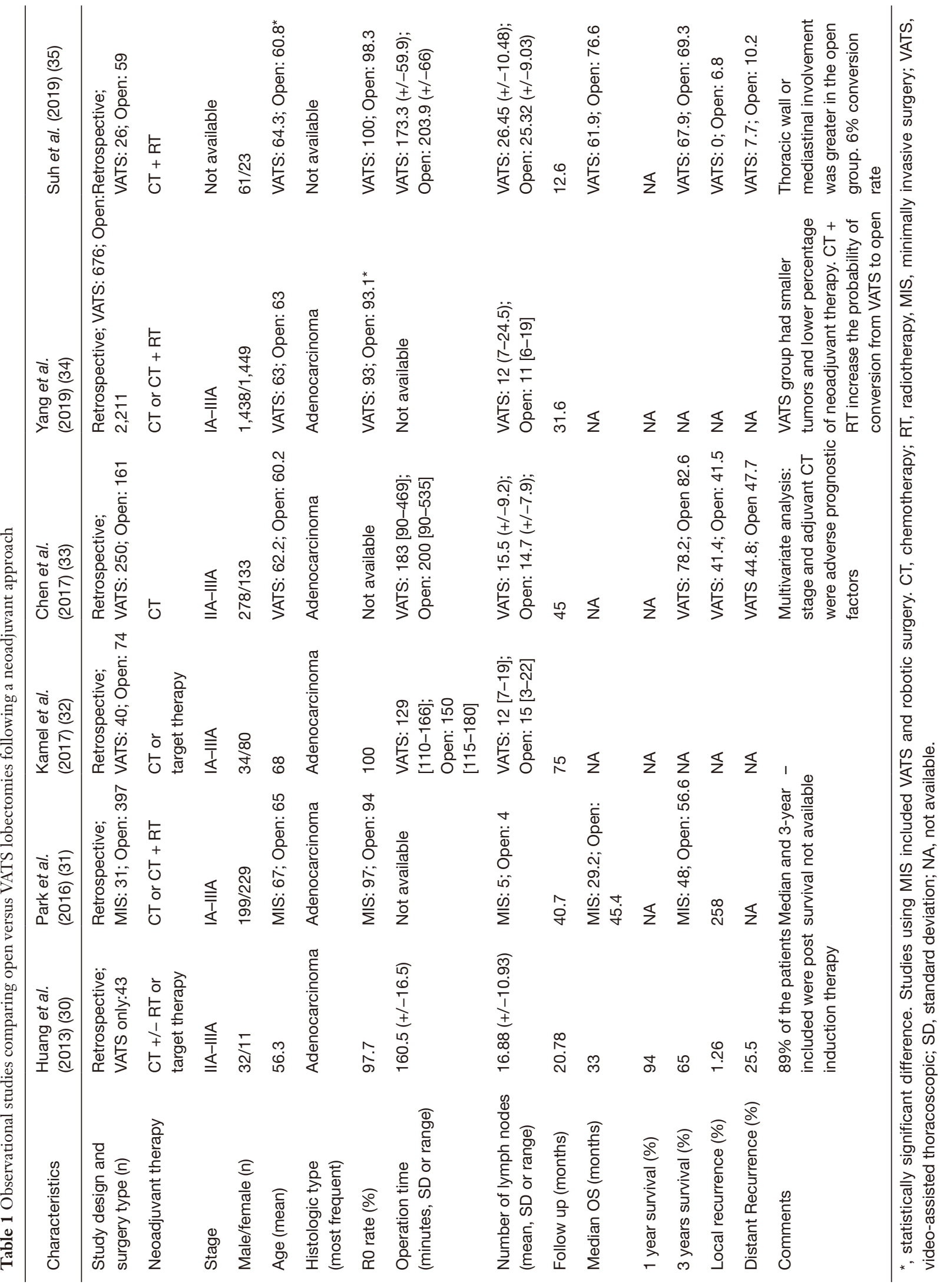


A recent publication by $\mathrm{Li}$ and colleagues, comparing 85 VATS with 36 robotic-assisted thoracic surgeries, found a greater number of lymph nodes sampled $(\mathrm{P}=0.01)$, and a shorter stay $(\mathrm{P}=0.01)$ with the robotic approach (41). Consistently, Dylewski et al. reported similar results using RATS in a cohort of 15 locally advanced lung cancer patients pretreated with chemotherapy and/or chemoradiation (40).

Despite the robotic approach advantages, some major contraindications should be considered, such as intrapericardial pneumonectomy, atrial resections, major vascular resection and reconstruction, extended chest wall resections, and masses with the minimum diameter larger than $8-10 \mathrm{~cm}$ requiring rib spreading to remove the mass itself (38). Similar to open surgery, large central tumors, multi-station lymph node compromise, and previous irradiation can challenge the surgical management of locally advanced NSCLC with a minimally invasive approach. In this context, Veronesi et al. described some useful Tips, Tricks, and pitfalls for a robotic approach that should be considered (38):

* Pay more attention to vascular dissection to avoid bleeding in patients with previous neoadjuvant treatment;

* When an elevated diaphragm is found, it can be useful a stitch to fix it to the chest wall at the level of 10th intercostal space in order to better dissect the hilar structures and the mediastinum;

* Use hemostatic materials to protect the dissected lymph node lodge and prevent bleeding.

\section{Cost-effectiveness of open, VATS and robotic approaches}

Although the study of surgical approaches in lung cancer was classically based on the medical effectiveness outcomes, the cost analysis is also crucial to expand accessibility. Interestingly, most of the studies analyzing the cost were based exclusively on early-stages. Deen et al. performed an exhaustive retrospective review on the cost between open, VATS, and robotic approaches in stage I or II NSCLC performed from 2008 to 2012 (42). The decision for a specific technique was based on surgeon preference. The "cost minimization" was developed utilizing the hospital's perspective, excluding indirect charges, such as salaries or insurance. They found that RATS had the lowest length of inpatient stay, but the longer operative time. A similar frequency of both major and minor complications was observed among all approaches. There was no cost difference between open versus VATS cases (Open: $\$ 15,036.32$ vs. VATS: $\$ 13,829.02, \mathrm{P}=0.227)$, and open versus robot-assisted surgery (Open: $\$ 15,036.32$ vs. RATS: $\$ 17,011.02 ; \mathrm{P}=0.059)$. However, it was found a significant difference in overall cost between robotic and VATS cases (RATS: $\$ 17,011.02$ vs. VATS: $\$ 13,829.02 ; \mathrm{P}<0.001$ ). As a result, all these findings challenge previous knowledge that exposed the open resection as significantly more expensive than VATS.

Given that most of the studies analyzing the economic impact of the different surgical interventions were performed almost exclusively on early lung cancer, it is imperative to expanded knowledge on the locally advanced setting. Decreasing operation room time, limiting unnecessary laboratory tests, and minimizing the need for intensive care would result in a significant hospital costs reduction.

\section{Conclusions}

The MIS is a new challenge approach for the extremely complex treatment of stage IIIA-N2 NSCLC patients. An appropriate staging and re-staging (tumor and mediastinal response) not only have an impact on the prognosis but also allows discriminating the potential beneficiaries of the different surgical techniques. In this context, it should be noticed that the 'unsuspected N2' subgroup has a more favorable prognosis compared to the 'N2 suspected' lymph node involvement.

Since the beginnings of the 90s, MIS expanded its indication and penetration in the lung cancer surgical field. Firstly, this approach was implemented for early-stage cases, but it has recently moved towards the treatment of locally advanced patients, mainly leading by its similar effectiveness compared with the traditional open surgery. MIS has demonstrated an impact in terms of extension of the lymph node dissection, complications rate, or operation time. Furthermore, MIS benefits were observed in early and locally advanced (IIIA-N2) NSCLC patients, including lower postoperative pain, lower inflammatory response, and decreased hospitalization stay. Interestingly, the robotic surgery approach seems to offer similar or even superior results than VATS, with the benefit of reducing the learning curve. However, VATS remains the most cost-effective minimally invasive technique for lung cancer surgery, and 
better cost-effectiveness data is imperatively needed for the implementation of the robotic approach.

\section{Acknowledgments}

Funding: None.

\section{Footnote}

Provenance and Peer Review: This article was commissioned by the Guest Editor (Mariano Provencio) for the series "Multimodal management of locally advanced N2 nonsmall cell lung cancer" published in Translational Lung Cancer Research. The article has undergone external peer review.

Conflicts of Interest: The author has completed the ICMJE uniform disclosure form (available at http://dx.doi. org/10.21037/tlcr.2020.03.27). The series "Multimodal management of locally advanced N2 non-small cell lung cancer" was commissioned by the editorial office without any funding or sponsorship. The author has no other conflicts of interest to declare.

Etbical Statement: The author is accountable for all aspects of the work in ensuring that questions related to the accuracy or integrity of any part of the work are appropriately investigated and resolved.

Open Access Statement: This is an Open Access article distributed in accordance with the Creative Commons Attribution-NonCommercial-NoDerivs 4.0 International License (CC BY-NC-ND 4.0), which permits the noncommercial replication and distribution of the article with the strict proviso that no changes or edits are made and the original work is properly cited (including links to both the formal publication through the relevant DOI and the license). See: https://creativecommons.org/licenses/by-ncnd $/ 4.0 /$.

\section{References}

1. Ettinger DS, Wood DE, Aisner DL, et al. Non-Small Cell Lung Cancer, Version 5.2017, NCCN Clinical Practice Guidelines in Oncology. J Natl Compr Canc Netw 2017;15:504-35.

2. Gaudet MA, D'Amico TA. Thoracoscopic Lobectomy for Non-small Cell Lung Cancer. Surg Oncol Clin N Am
2016;25:503-13.

3. Hirji SA, Osho A, Balderson SS, et al. Thoracoscopic lobectomy after induction therapy—a paradigm shift? J Vis Surg 2017;3:189.

4. Yang CFJ, D'Amico TA. Open, thoracoscopic and robotic segmentectomy for lung cancer. Ann Cardiothorac Surg 2014;3:142-52.

5. Yang CFJ, Meyerhoff RR, Mayne NR, et al. Long-term survival following open versus thoracoscopic lobectomy after preoperative chemotherapy for non-small cell lung cancer. Eur J Cardiothorac Surg 2016;49:1615-23.

6. Yang CFJ, Kumar A, Gulack BC, et al. Long-term outcomes after lobectomy for non-small cell lung cancer when unsuspected pN2 disease is found: A National Cancer Data Base analysis. J Thorac Cardiovasc Surg 2016;151:1380-8.

7. Yang CJ, Mayne NR, Wang H, et al. Outcomes of Major Lung Resection After Induction Therapy for Non-Small Cell Lung Cancer in Elderly Patients. Ann Thorac Surg 2016;102:962-70.

8. Gonzalez-Rivas D, Fieira E, Delgado M, et al. Is uniportal thoracoscopic surgery a feasible approach for advanced stages of non-small cell lung cancer? J Thorac Dis 2014;6:641-8.

9. Sanchez-Lorente D, Guzman R, et al. N2 disease in nonsmall-cell lung cancer: straight to surgery? Future Oncol 2018;14:13-6.

10. Cerfolio RJ, Maniscalco L, Bryant AS. The treatment of patients with stage IIIA non-small cell lung cancer from N2 disease: who returns to the surgical arena and who survives. Ann Thorac Surg 2008;86:912-20.

11. van Meerbeeck JP, Kramer GWPM, Van Schil PEY, et al. Randomized controlled trial of resection versus radiotherapy after induction chemotherapy in stage IIIA-N2 non-small-cell lung cancer. J Natl Cancer Inst 2007;99:442-50.

12. Albain KS, Swann RS, Rusch VW, et al. Radiotherapy plus chemotherapy with or without surgical resection for stage III non-small-cell lung cancer: a phase III randomised controlled trial. Lancet 2009;374:379-86.

13. Detterbeck F. What to do with "Surprise" N2?: intraoperative management of patients with non-small cell lung cancer. J Thorac Oncol 2008;3:289-302.

14. Detterbeck FC, Rivera PM, Socinski M, et al. Diagnosis and Treatment of Lung Cancer: An Evidence-Based Guide for the Practicing Clinician. In Michigan, USA: W.B. Saunders Company, 2001.

15. Wei S, Asamura H, Kawachi R, et al. Which is the 
better prognostic factor for resected non-small cell lung cancer: the number of metastatic lymph nodes or the currently used nodal stage classification? J Thorac Oncol 2011;6:310-8.

16. Li GL, Zhu Y, Zheng W, et al. Analysis of factors influencing skip lymphatic metastasis in pN2 non-small cell lung cancer. Chin J Cancer Res 2012;24:340-5.

17. Zhang LM, Zhang Z, Wang C. Clinical and prognostic analysis of skip N2 metastases in stage IIIA-N2 non-small cell lung cancer. Zhonghua Wai Ke Za Zhi 2010;48:780-3.

18. Prenzel KL, Mönig SP, Sinning JM, et al. Role of skip metastasis to mediastinal lymph nodes in non-small cell lung cancer. J Surg Oncol 2003;82:256-60.

19. Li X, Li X, Fu X, et al. Survival benefit of skip metastases in surgically resected N2 non-small cell lung cancer: A multicenter observational study of a large cohort of the Chinese patients. Eur J Surg Oncol 2020;46:1874-81

20. Veronesi G, Park B, Cerfolio R, et al. Robotic resection of Stage III lung cancer: an international retrospective study. Eur J Cardiothorac Surg 2018;54:912-9.

21. Lee PC, Kamel M, Nasar A, et al. Lobectomy for NonSmall Cell Lung Cancer by Video-Assisted Thoracic Surgery: Effects of Cumulative Institutional Experience on Adequacy of Lymphadenectomy. Ann Thorac Surg 2016;101:1116-22.

22. Swanson SJ, Herndon JE, D'Amico TA, et al. Videoassisted thoracic surgery lobectomy: report of CALGB 39802--a prospective, multi-institution feasibility study. J Clin Oncol 2007;25:4993-7.

23. Boffa DJ, Kosinski AS, Paul S, et al. Lymph node evaluation by open or video-assisted approaches in 11,500 anatomic lung cancer resections. Ann Thorac Surg 2012;94:347-53; discussion 353.

24. Demmy TL, Yendamuri S, D'Amico TA, et al. Oncologic Equivalence of Minimally Invasive Lobectomy: The Scientific and Practical Arguments. Ann Thorac Surg 2018;106:609-17.

25. Taioli E, Lee DS, Lesser M, et al. Long-term survival in video-assisted thoracoscopic lobectomy vs open lobectomy in lung-cancer patients: a meta-analysis. Eur J Cardiothorac Surg 2013;44:591-7.

26. Kirby TJ, Mack MJ, Landreneau RJ, et al. Lobectomy-video-assisted thoracic surgery versus muscle-sparing thoracotomy. A randomized trial. J Thorac Cardiovasc Surg. 1995;109:997-1001.

27. Sugi K, Kaneda Y, Esato K. Video-assisted thoracoscopic lobectomy achieves a satisfactory long-term prognosis in patients with clinical stage IA lung cancer. World J Surg
2000;24:27-30.

28. Xue Y, Wang YY, Zhang K, et al. A Study of Complete Video-Assisted Thoracoscopic Surgery Lobectomy in Treatment of Elderly Patients with Non-Small Cell Lung Cancer: Curative Effect and Impact on Clinical Prognosis. Cell Biochem Biophys 2015;73:399-404.

29. Wang Z, Pang L, Tang J, et al. Video-assisted thoracoscopic surgery versus muscle-sparing thoracotomy for non-small cell lung cancer: a systematic review and meta-analysis. BMC Surg 2019;19:144.

30. Huang J, Xu X, Chen H, et al. Feasibility of complete video-assisted thoracoscopic surgery following neoadjuvant therapy for locally advanced non-small cell lung cancer. J Thorac Dis 2013;5:S267-73.

31. Park BJ, Yang HX, Woo KM, et al. Minimally invasive (robotic assisted thoracic surgery and video-assisted thoracic surgery) lobectomy for the treatment of locally advanced non-small cell lung cancer. J Thorac Dis 2016;8:S406-413.

32. Kamel MK, Nasar A, Stiles BM, et al. Video-Assisted Thoracoscopic Lobectomy Is the Preferred Approach Following Induction Chemotherapy. J Laparoendosc Adv Surg Tech A 2017;27:495-500.

33. Chen K, Wang X, Yang F, et al. Propensity-matched comparison of video-assisted thoracoscopic with thoracotomy lobectomy for locally advanced non-small cell lung cancer. J Thorac Cardiovasc Surg 2017;153:967976.e2.

34. Yang CJ, Nwosu A, Mayne NR, et al. A Minimally Invasive Approach to Lobectomy After Induction Therapy Does Not Compromise Survival. Ann Thorac Surg 2020;109:1503-11.

35. Suh JW, Park SY, Lee CY, et al. Feasibility and surgical outcomes of video-assisted thoracoscopic pulmonary resection in patients with advanced-stage lung cancer after neoadjuvant chemoradiotherapy. Thorac Cancer 2019;10:1241-7.

36. Gonzalez D, Paradela M, Garcia J, et al. Single-port videoassisted thoracoscopic lobectomy. Interact Cardiovasc Thorac Surg 2011;12:514-5.

37. Park BJ, Flores RM, Rusch VW. Robotic assistance for video-assisted thoracic surgical lobectomy: technique and initial results. J Thorac Cardiovasc Surg 2006;131:54-9.

38. Veronesi G, Novellis P, Difrancesco O, et al. Robotic assisted lobectomy for locally advanced lung cancer. J Vis Surg 2017;3:78.

39. Cerfolio RJ, Bryant AS, Skylizard L, et al. Initial consecutive experience of completely portal robotic 
pulmonary resection with 4 arms. J Thorac Cardiovasc Surg 2011;142:740-6.

40. Dylewski MR, Ohaeto AC, Pereira JF. Pulmonary resection using a total endoscopic robotic video-assisted approach. Semin Thorac Cardiovasc Surg 2011;23:36-42.

41. Li C, Hu Y, Huang J, et al. Comparison of robotic-assisted lobectomy with video-assisted thoracic surgery for stage

Cite this article as: Patané AK. Minimal invasive surgery in locally advanced N2 non-small cell lung cancer. Transl Lung Cancer Res 2021;10(1):519-528. doi: 10.21037/tlcr.2020.03.27
IIB-IIIA non-small cell lung cancer. Transl Lung Cancer Res 2019;8:820-8.

42. Deen SA, Wilson JL, Wilshire CL, et al. Defining the cost of care for lobectomy and segmentectomy: a comparison of open, video-assisted thoracoscopic, and robotic approaches. Ann Thorac Surg 2014;97:1000-7. 